\title{
Occurrence of Interspecific Mating between Two Species of Danaus Kluk, 1780 (Lepidoptera: Nymphalidae) in Nature
}

\author{
Sarika Baidya $\left(\mathbb{D},{ }^{1}\right.$ Dipendra Nath Basu, ${ }^{2,3}$ Souparno Roy, ${ }^{1,4}$ and Arjan Basu Roy ${ }^{1}$ \\ ${ }^{1}$ Nature Mates-Nature Club, 6/7 Bijoygarh Road, Kolkata, West Bengal 700032, India \\ ${ }^{2}$ National Centre for Biological Sciences, Tata Institute of Fundamental Research, Bellary Road, Bangalore, \\ Karnataka 560065, India \\ ${ }^{3}$ SASTRA University, Thanjavur, Tamil Nadu, India \\ ${ }^{4}$ Presidency University, 86/1 College Street, Kolkata, West Bengal 700073, India
}

Correspondence should be addressed to Sarika Baidya; bukun.nm@gmail.com

Received 30 November 2017; Accepted 28 February 2018; Published 1 April 2018

Academic Editor: Anna-Karin Borg-Karlson

Copyright (C) 2018 Sarika Baidya et al. This is an open access article distributed under the Creative Commons Attribution License, which permits unrestricted use, distribution, and reproduction in any medium, provided the original work is properly cited.

Mating across species occurs rarely in nature, which contends prevalent idea of biological species concept. Throughout species range, mating pattern varies and reproductive barriers are also not fixed among different species. In this study, two instances of interspecific mating between two widely common Nymphalid Tiger butterflies (Danaus Kluk, 1780) in Indian region are reported. Observations imply lack of absolute reproductive barriers, where possible interplay exists among prezygotic and postzygotic isolating factors compensating each other in order to restrain interspecific hybridization.

\section{Introduction}

Biological species concept [1] is a widely accepted hypothesis prevailing evolutionary ideas regarding species and speciation in the last century. It delineates species as a population of interbreeding individuals restrained from mating with other such populations $[1,2]$. This concept is profoundly based on the absolute reproductive isolation between two species. Natural history and behavioral insights divide reproductive barriers into prezygotic and postzygotic isolating factors [2]. Effectiveness of these factors varies quiet a lot as barriers among different organisms [3-5]. Some of these barriers are not very effective in maintaining reproductive isolation between two species resulting in interspecific hybridization.

Natural history records are bringing forth instances of interspecific mating, but it is considered to be a rare and stochastic phenomenon in nature. These evidences reveal presence of leaky reproductive barrier, contesting the idea of absolute isolation. Biological species concept does not support the idea of viable hybrid species, but there are a few examples of hybrid species populations in nature [6]. In different organisms, interspecific hybridization is an instrumental factor for speciation and thus has immense evolutionary significance [7-9].

Moths and butterflies also have been found to have interspecific pairings. Apart from the artificially induced interspecific crosses [10-12], naturalists reported interspecific, intergeneric, and interfamilial mating in different groups of Lepidopteran insects $[3,12-16]$. Interspecific pairings have been reported in Nymphalid [17-19], Lycaenid [20], Pierid [21], and Papilionid [6, 13, 14, 22] butterflies. Preceding studies on mating patterns suggested successful artificial hybridization $[10,11,23-25]$ and $6 \%$ chances of natural interspecific mating in butterfly genus Papilio Linnaeus, 1758 [26]. Overall frequency estimation of interspecific mating has been doubled from $0.7 \%$ to $1.5 \%$ in North American butterflies over 50 years $[3,20]$. Sometimes, chemical cues also induced such crossspecific mating [27].

There are multiple conjectures of congeneric hybridizations in Papilionid and Lycaenid butterflies proposed by earlier taxonomists working on Indian butterflies [28, 29]. Occurrence of intergeneric pairing in different Lycaenid butterflies has been reported in recent years $[15,30]$. We are not aware of any recent report on interspecific mating in 


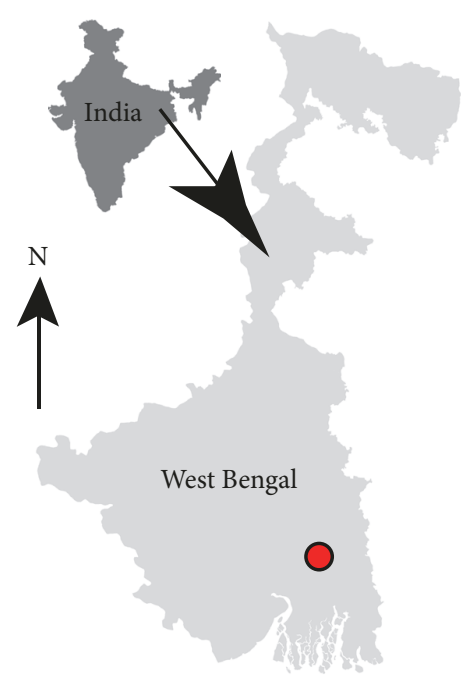

(a)

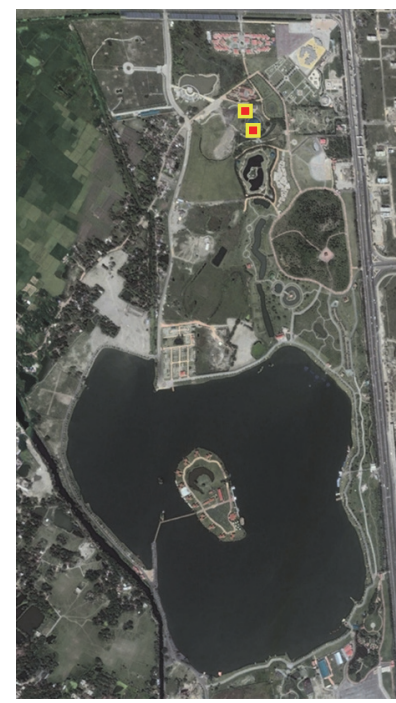

(b)

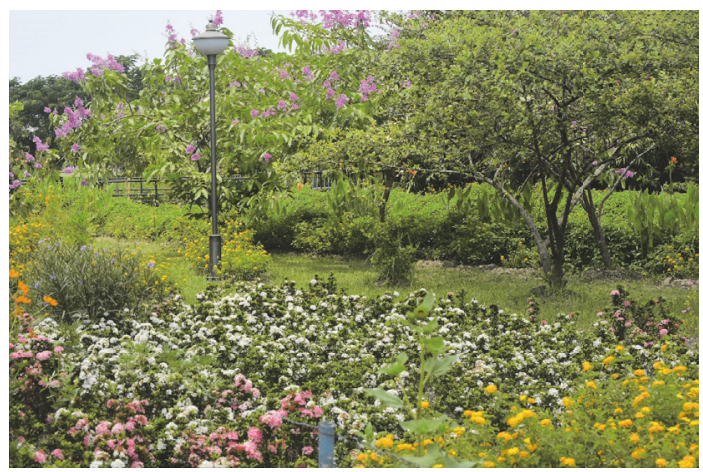

(c)

Figure 1: Location and surrounding habitat of intraspecific mating. (a) Location of Eco Park in West Bengal, India. (b) On the map, the red and yellow spots show the GPS taken for the observation of two occurrences (map courtesy: Google Earth, Google LLC.). (c) Habitat of butterfly garden and presence of butterfly host plants and nectar plants.

Indian Nymphalid butterflies. In this article, we report for the first time occurrence of interspecific mating between two Danaus butterfly species in nature: $D$. chrysippus (Linnaeus, 1758 ) and D. genutia (Cramer, 1779).

\section{Materials and Methods}

We observed two instances of interspecific mating between Danaus chrysippus and D. genutia in Eco Tourism Park butterfly garden in Kolkata (Figure 1). Photographs were taken with Nikon P510 camera and GPS of the location was recorded during the observation.

After mating, individuals were provided with their host plants and nectar plants inside a rearing cage making an artificial habitat for them. Females were kept in the enclosure with proximity of host plant to induce them for laying eggs. Eggs were subsequently reared in the standard manner.

In order to see the extent of lock and key mechanism playing role in interspecies mating, the $D$. chrysippus and $D$. genutia males have been dissected for ideal genitalia morphology in these two species. To check probable variation in external genitalia morphology between parents and offspring of this interspecific pairing, if any, we have dissected the male and female offspring reared out of the brood resulting from interspecific mating. Both of the male and female genitalia have been dissected with $10 \% \mathrm{KOH}$. Photographs of genitalia were taken in Leica microscope and stacked multiple focal plane in CombineZM [31] to acquire better depth of field. Dissected materials have been preserved in glycerol.

\section{Result}

The first instance was observed and photographed on 19 April 2015 inside Eco Tourism Park butterfly garden, Kolkata $\left(22.607^{\circ} \mathrm{N}, 88.465^{\circ} \mathrm{E}\right)$ (Figure $\left.1(\mathrm{~b})\right)$ at $15: 15$ hrs., where a male $D$. genutia was found to mate with a female D. chrysippus in flight for approximately fifteen minutes and then they settled down on axillary tendril of Passiflora foetida Linnaeus (Figure 2(a)). There, they continued the mating till 17:06 hrs. and surprisingly after that the male died before withdrawal of its copulatory organ from the body of female individual. We collected the mating pair and brought them in our 


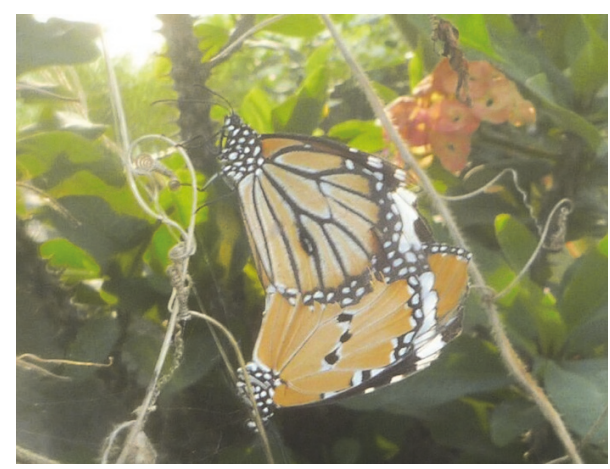

(a)

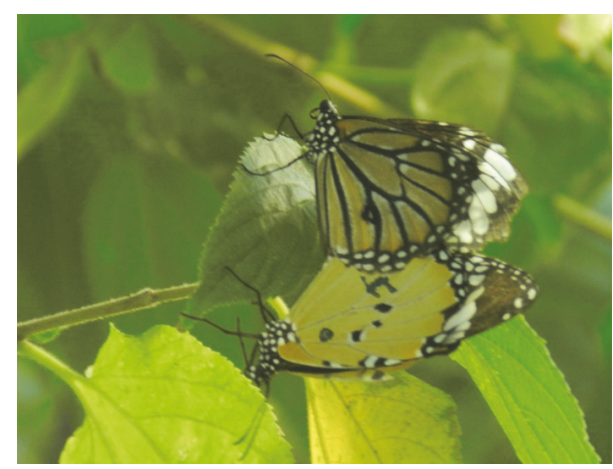

(b)

FIGURE 2: Interspecific mating in D. chrysippus and D. genutia. (a) First occurrence in 2015 and (b) second instance in 2016.

laboratory, where we detached the mating pair and observed the female $D$. chrysippus in insect rearing cage providing Calotropis gigantea (Linnaeus) Dryand. as host plant and Lantana camara Linnaeus as nectaring plant. The female survived normally and laid 54 eggs on 20 April from 9:08 hrs. to 12:50 hrs. but none of the eggs hatched. The female died on 21 April 2015.

The second instance of mating was recorded on 26 May 2016 in Eco Tourism Park butterfly garden, Kolkata $\left(22.608^{\circ} \mathrm{N}, 88.465^{\circ} \mathrm{E}\right)$ (Figure 1(b)) at 16:10 hrs., where, like the previous occurrence, the male individual was D. genutia and the female was $D$. chrysippus. The mating continued for 50 minutes on the leaf of Trema orientalis (Linnaeus) Blume (Figure 2(b)) after which the pair was observed further in an insect-rearing cage providing artificial habitat as the above. Both of the butterflies survived as usual but, on the next day, the male died at 11:00 hrs. On the same day, the female laid 14 eggs on the bud of Calotropis gigantea (Linnaeus) Dryand. between 14:30 hrs. and 14:55 hrs. and it died on 29 May. 12 of the laid eggs hatched on 30 May and the remaining two eggs hatched on the next day. All the hatched caterpillars survived and completed their moulting to 5th instar. The larval stage and pupal stage continued for eight days and seven days, respectively. Only 4 individuals emerged successfully and appeared to be $D$. chrysippus, among which two were males and two were females. One male and one female were marked, released in nature, and observed for 10 days. The genitalia of the remaining two butterflies along with the mating pair were dissected under dissection microscope and observed.

External male genitalia morphology in both species is distinguishable by the overall structure of genital capsule, shape of clasp, and aedeagus. In D. chrysippus valves are broad and heavily sclerotized, with distal processes bent ventrally, and fused with vinculum and tegumen (Figure $3 \mathrm{i}(\mathrm{a})$ ). Additionally, the aedeagus has two sclerotized, serrated processes at the distal part near cornuti (Figure $3 \mathrm{i}(\mathrm{b})$ ). Contrarily, in $D$. genutia valves are short, downwardly curved, and fused ventrally with vinculum and the part of tegumen is broader than the other species (Figure 3 iii(a)). In aedeagus, there are two rows of dentation at the distal part but sclerotized process is absent (Figure 3 iii(b)). Everted vesica shows distinct dentation pattern in both species. While comparing genitalia morphology of male offspring from second instance with ideal $D$. chrysippus male genitalia, checking probable variation if any, we found no differences, except a slight variation in the dentation of the distal sclerotized process on aedeagus (Figure $3 \mathrm{ii}(\mathrm{b})$ ). Genitalia of female offspring shows no such variation (Figure 3 iv $(a, b)$ ).

\section{Discussion}

Danaus chrysippus and D. genutia are closely related species and are widely overlapping in spatial distribution throughout southern to southeastern Asia and Australia [32]. To prevent interspecific genetic exchange, where two species overlap spatially and temporally, selection should impose drastic variability in the reproductive barriers, ensuring incompatibility between species populations. To the contrary, we see two events of interspecific pairing within a couple of years between these two Danaus species, indicating lack of absolute reproductive barriers.

From a perspective of sexual selection, in butterflies, females are the choosy sex imposing selection on the males. As we have seen in both cases, the mating pairs were male $D$. genutia and female D. chrysippus; there lies possibility of relaxed mate preference in females (which may be individualistic) of D. chrysippus or the cues (namely, visual, chemical, and tactile) for mate selection overlap significantly in these two species. On the other hand, components of genitalia in female D. chrysippus may not be functionally selective for different genitalia structures in males of both species, resulting in interspecific pairing.

External male genitalia morphology has been treated as a proxy for prezygotic barrier. According to "lock and key" hypothesis, male and female genitalia are compatible within a species but incompatible between species [33]. But there are no profound empirical findings on the functional role of key components of genitalia. Several studies showed intraspecific variation in such characters [34-36]. This clearly represents lack of an ideal lock and key mechanism and raises questions about its significance in maintaining reproductive isolation. As we compared genitalia of offspring and D. chrysippus, we 


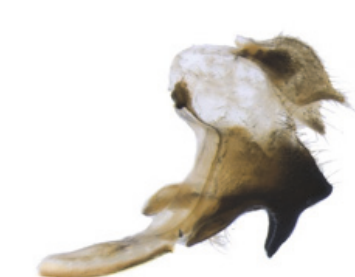

i(a)

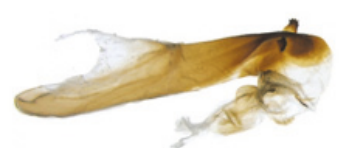

i(b)

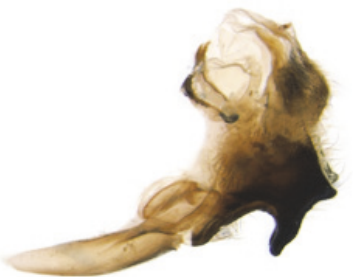

ii(a)

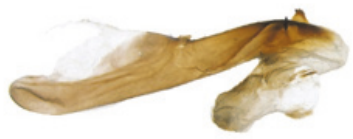

ii(b)

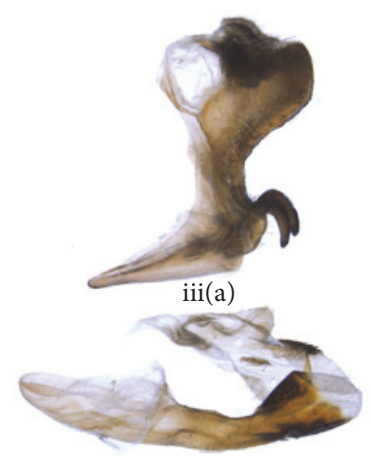

iii(b)
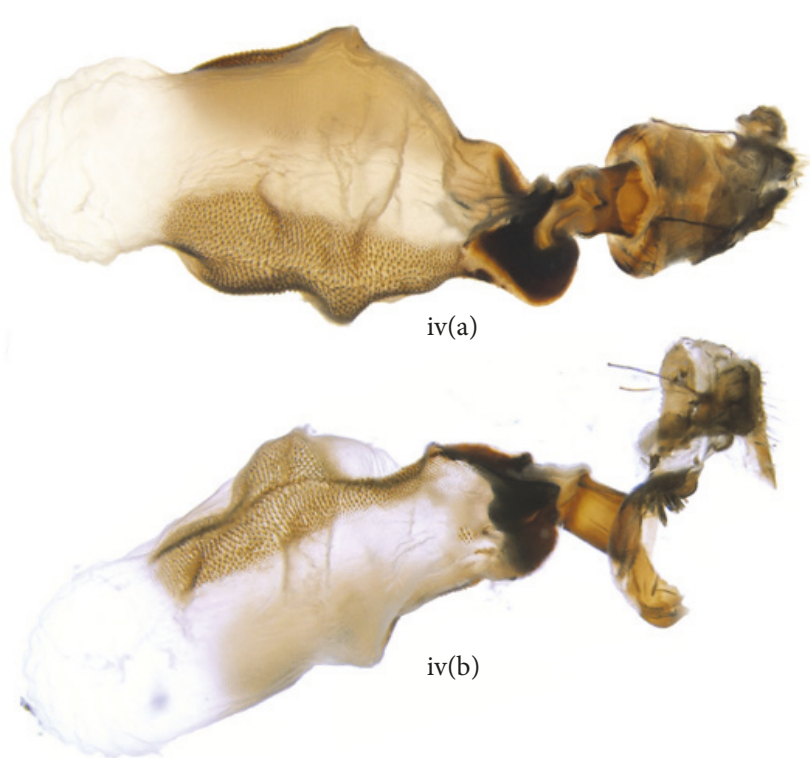

FIGURE 3: Genitalia morphology. Male genitalia of D. chrysippus: i(a) lateral view of genital capsule, i(b) aedeagus; male genitalia of offspring from second instance: ii(a) lateral view of genital capsule, ii(b) aedeagus; male genitalia of D. genutia: iii(a) lateral view of genital capsule, iii(b) aedeagus; genitalia of female offspring which is similar to D. chrysippus: iv(a) dorsal view and iv(b) lateral view.

found very minor variation which may be intrapopulation variation in $D$. chrysippus.

In interspecific pairing, often it has been noticed that transfer of spermatheca does not occur. But in our scenario, spermatheca was present in female after mating. Insects including butterflies have another line of prezygotic barrier by means of females' ability to choose from multiple spermathecae present in bursa copulatrix [37]. As we have seen that, in the second occurrence, the offspring were $D$. chrysippus like their female parent, this may imply that the female was mated earlier with $D$. chrysippus male and chose that spermathecae over the spermatheca be transferred by the male D. genutia. In the first scenario, the mated female laid eggs but none hatched; this may be because either female laid unfertilized eggs without utilizing the spermatheca or postzygotic barrier played key role, where zygote lacked homologous pairing of chromosomal entities and led to nonviability.

Therefore, in Danaus butterflies, ideal lock and key mechanism may not be present but other factors like selective spermatheca usage by females and postzygotic barrier play key role in restraining gene flow between two species.

\section{Conflicts of Interest}

The authors declare that there are no conflicts of interest regarding the publication of this paper.

\section{Authors' Contributions}

Sarika Baidya and Dipendra Nath Basu contributed equally to this work.

\section{Acknowledgments}

The authors are thankful to WBHIDCO, Kolkata, for their fund in maintaining Eco Tourism Park butterfly garden. The authors are also very thankful to Sayantani Bag, Ananya Sarkar, Diptashikha Chowdhury, and all the members of Nature Mates-Nature Club. Special thanks are due to Ms. Devsena Roychaudhury, Mr. Tarun Karmakar, Mr. Souryadeep Mukherjee, and Dr. Krushnamegh Kunte for their valuable guidance and endless inspiration. 


\section{References}

[1] E. Mayr, Systematics and the Origin of Species, Columbia University Press, New York, NY, USA, 1st edition, 1942.

[2] E. Mayr, Animal Species and Evolution, Harvard University Press, Cambridge, Mass, USA, 1st edition, 1965.

[3] J. Downey, "Inter-specifc pairing in Lycaenidae," Journal of the Lepidopterists' Society, vol. 16, pp. 235-237, 1962.

[4] Y. Sato, J. A. J. Breeuwer, M. Egas, and M. W. Sabelis, "Incomplete premating and postmating reproductive barriers between two parapatric populations of a social spider mite," Experimental and Applied Acarology, vol. 65, no. 3, pp. 277-291, 2015.

[5] M. B. B. Miranda, D. J. Innes, and R. J. Thompson, "Incomplete reproductive isolation in the blue mussel (mytilus edulis and $\mathrm{m}$. trossulus) hybrid zone in the northwest atlantic: role of gamete interactions and larval viability," The Biological Bulletin, vol. 218, no. 3, pp. 266-281, 2010.

[6] C. A. Clarke and P. M. Sheppard, "Further observations on hybrid swallowtails," Entomological Records, vol. 65, p. 12, 1953.

[7] J. Mavárez, C. A. Salazar, E. Bermingham, C. Salcedo, C. D. Jiggins, and M. Linares, "Speciation by hybridization in Heliconius butterflies," Nature, vol. 441, no. 7095, pp. 868-871, 2006.

[8] T. Capblancq, L. Després, D. Rioux, and J. Mavárez, "Hybridization promotes speciation in Coenonympha butterflies," Molecular Ecology, vol. 24, no. 24, pp. 6209-6222, 2015.

[9] J. Mallet, "Hybrid speciation," Nature, vol. 446, no. 7133, pp. 279-283, 2007.

[10] C. A. Clarke, "Handpairing of Papilio machaon in February," Entomological Records, vol. 64, pp. 98-100, 1952.

[11] C. A. Clarke and P. M. Sheppard, "The breeding in captivity of the hybrid papilio rutulus female $\mathrm{x}$ papilio glaucus male, the lepidopterists' news," The Lepidopterists' News, vol. 9, no. 2-3, pp. 46-48, 1955.

[12] C. A. Clarke, A. Cronin, W. Francke et al., "Mating attempts between the Scarlet Tiger Moth, Callimorpha dominula L., and the Cinnabar Moth, Tyria jacobaeae L. (Lepidoptera: Arctiidae), involve a common sex pheromone composition," Experientia, vol. 52, no. 6, pp. 636-638, 1996.

[13] D. L. Hancock, "Classification of the Papilionid (Lepidoptera): a phylogenetic approach," Smithersia, vol. 2, p. 48, 1983.

[14] D. Hancock, “The Princeps nireus group of swallowtails (Lepidoptera: Papilionidae), systematics, phylogeny and biogeography," Arnoldia Zimbabwe, vol. 9, pp. 181-215, 1984.

[15] M. Bhakare and P. Smetacek, "Two instances of inter-generic mating by Lycaenidae (Lepidoptera) in Maharashtra, India," The Journal of Research on the Lepidoptera, vol. 43, pp. 23-25, November.

[16] N. M. Collins and M. G. Morris, "Threatened Swallowtail Butterflies of the World," in The IUCN Red Data Book. IUCN, Gland Cambridge, 1985.

[17] A. P. Platt, G. W. Rawson, and G. Balogh, "Interspecific hybridization involving Limenitis archippus and its congeneric species (Nymphalidae)," Journal of the Lepidopterists' Society, vol. 32, pp. 289-303, 1978.

[18] R. Arbogast, "Capture of a hybrid Limenitis arthemis x L. archippus (Nymphalidae) in southern Georgia," Journal of the Lepidopterists' Society, vol. 30, p. 4, 1976.

[19] L. Spitzer, J. Beneš, P. Vrba, and M. Zlatník, “Three observation of interspecific mating attempts by males of the Meadow Brown (Maniola jurtina (Linnaeus, 1758)) in the wild (Lepidoptera, Nymphalidae: Satyrinae, Heliconiinae)," Nachrichten des Entomologischen Vereins Apollo, vol. 31, no. 3, pp. 166-168, 2010.
[20] W. Wright, Butterflies of the West Coast, Wright, Los Angeles, Calif, USA, 2nd edition, 1906.

[21] R. C. Priestaf, "Hybrid between Colias eurytheme and Colias harfordii (Pieridae) captured in California," Journal of the Lepidopterists' Society, vol. 28, p. 358, 1974.

[22] W. H. Wagner Jr, "A probable natural hybrid of Papilio eurymedon and P. rutulus (Papilionidae) from Idaho," Journal of the Lepidopterists' Society, vol. 22, pp. 226-228, 1978.

[23] R. Blanchard and H. Descimon, "Hybridization between two species of swallowtails, meiosis mechanism and the genesis of gynandromorphs," Journal of the Lepidopterists' Society, vol. 42, no. 2, pp. 94-102, 1988.

[24] C. A. Clarke and P. M. Sheppard, "A Further Report on the Genetics of the Machaon Group of Swallowtail Butterflies," Evolution, vol. 10, no. 1, p. 66, 1956.

[25] C. F. M. Swynnerton, "Evidence of Mendelian heredity in Papilio dardanus," pp. 30-33, 1919.

[26] F. A. H. Sperling, "Natural hybrids of Papilio (Insecta: Lepidoptera): poor taxonomy or interesting evolutionary problem?" Canadian Journal of Zoology, vol. 68, no. 8, pp. 1790-1799, 1990.

[27] B. M. Brennan, "Attraction of Ereunetis simulans (Lepidoptera: Tineidae) to the sex attractant of peachtree borer, Sanninoidae exitiosa (Lepidoptera: Sesiidae," in Proceedings of Hawaiian Entomological Society, vol. 22, pp. 457-460, 1977.

[28] W. H. Evans, The Identification of Indian Butterflies, Bombay Natural History Society, 2nd edition, 1932.

[29] M. A. Wynter-Blyth, Butterflies of the Indian Region, Bombay Natural History Society, 1st edition, 1957.

[30] P. Smetacek, "Batesian mimic butterflies taken in by their models and the mimetic status of Argyreus hyperbius L. (Nymphalidae)," Journal of the Bombay Natural History Society, vol. 102, no. 3, pp. 362-363, 2005.

[31] A. Hadley, "CombineZM," http://www.hadleyweb.pwp.blueyonder.co.uk, 2017.

[32] M. Savela, "Funet Lepidoptera," http://www.nic.funet.fi/pub/ sci/bio/life/insecta/lepidoptera/ditrysia/papilionoidea/index .html, 2016.

[33] L. Dufour, “Anatomie générale des diptères," Annales des Sciences Naturelles, vol. 1, pp. 244-264, 1844.

[34] D. Goulson, "Variation in the genitalia of the butterfly Maniola jurtina (Lepidoptera: Satyrinae)," Zoological Journal of the Linnean Society, vol. 107, no. 1, pp. 65-71, 1993.

[35] T. M. Gilligan and J. W. Wenzel, "Extreme intraspecific variation in Hystrichophora (Lepidoptera: Tortricidae) genitalia - Questioning the lock-and-key hypothesis," Annales Zoologici Fennici, vol. 45, no. 6, pp. 465-477, 2008.

[36] A. Caldas, "Notes on the male genitalia of the Anaea ryphea Anaea eurypyle complex (Nymphalidae)," Journal of the Lepidopterists' Society, vol. 51, no. 1, pp. 83-90, 1997.

[37] N. Wedell, "Female remating in butterflies: Interaction between female genotype and nonfertile sperm," Journal of Evolutionary Biology, vol. 14, no. 5, pp. 746-754, 2001. 


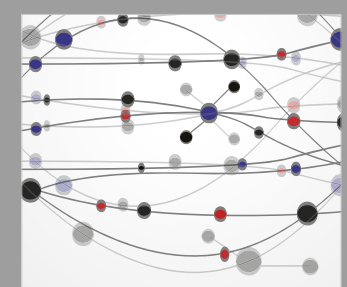

The Scientific World Journal
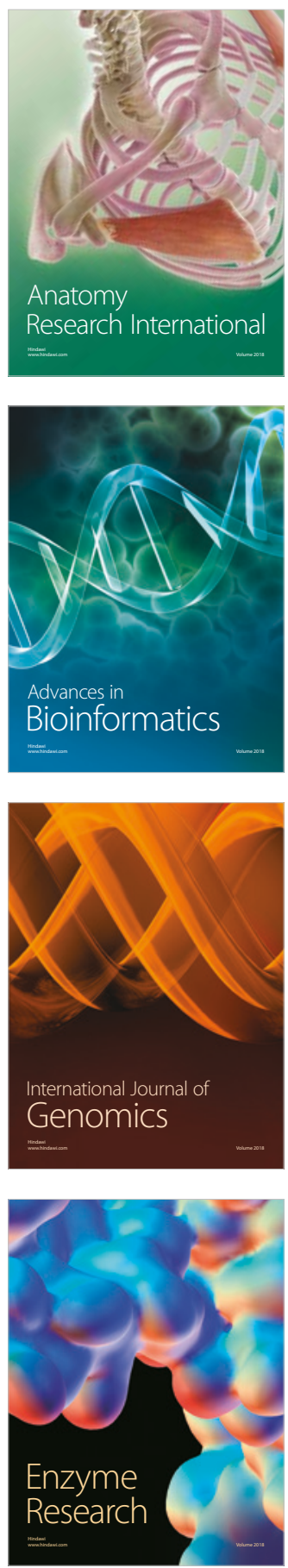
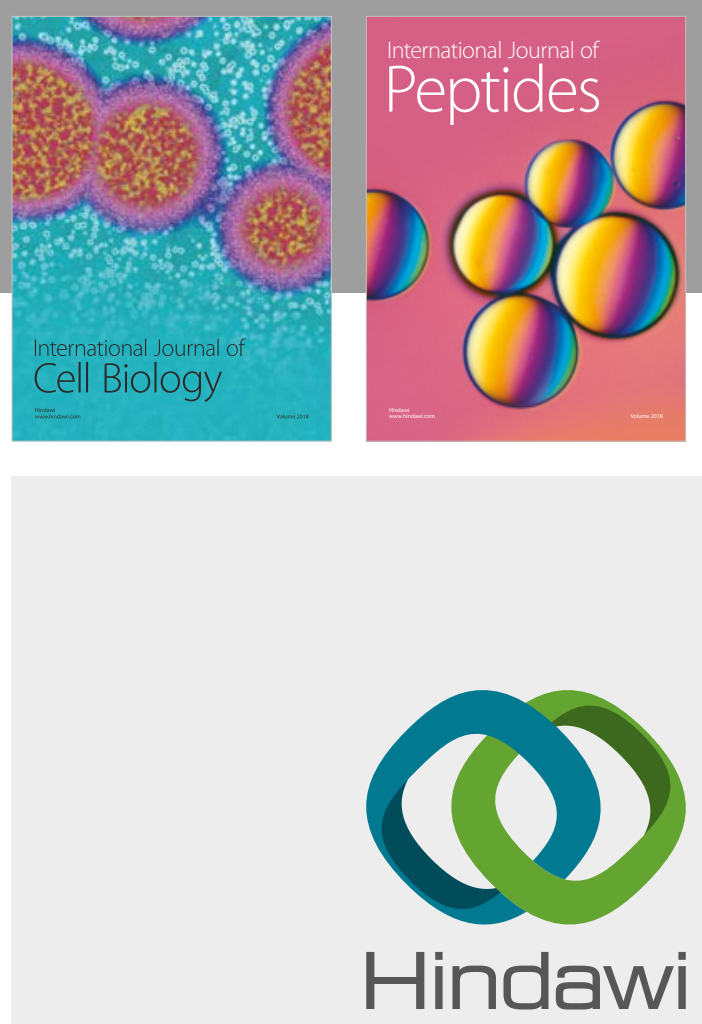

Submit your manuscripts at

www.hindawi.com
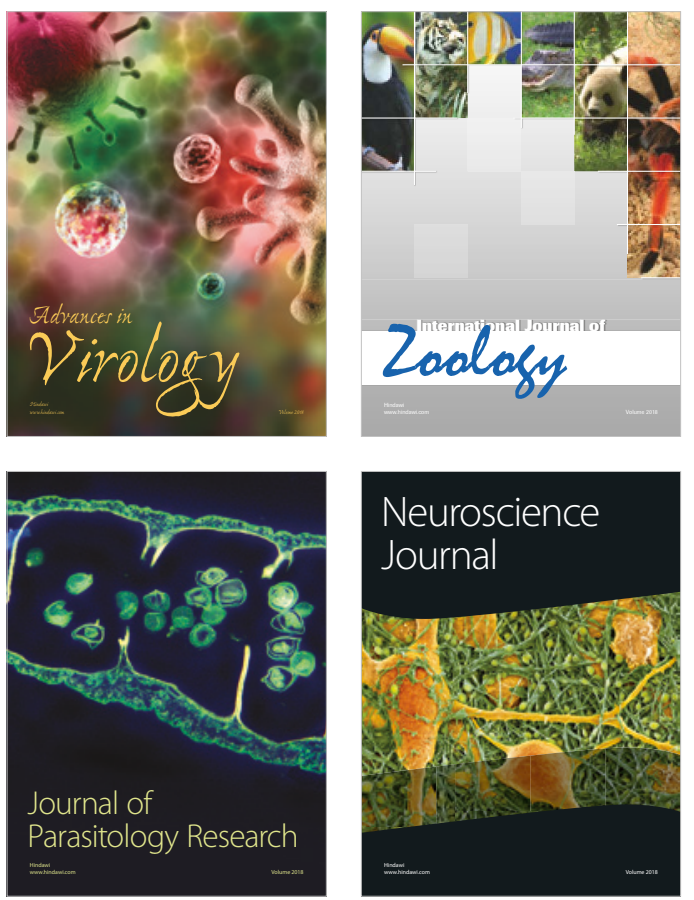
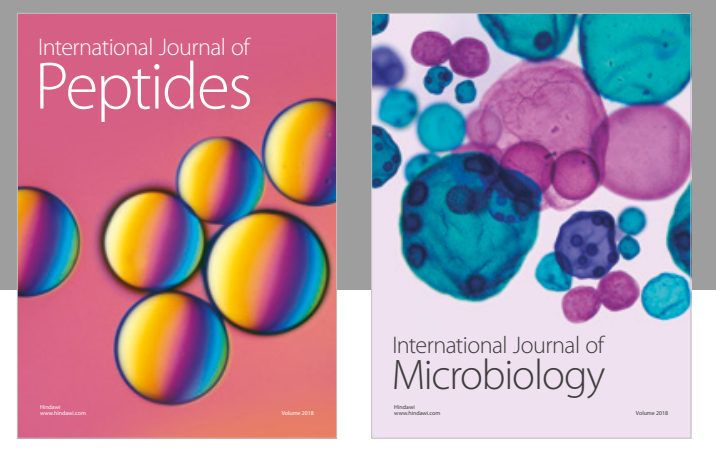

nternational Journal of Microbiology
Journal of
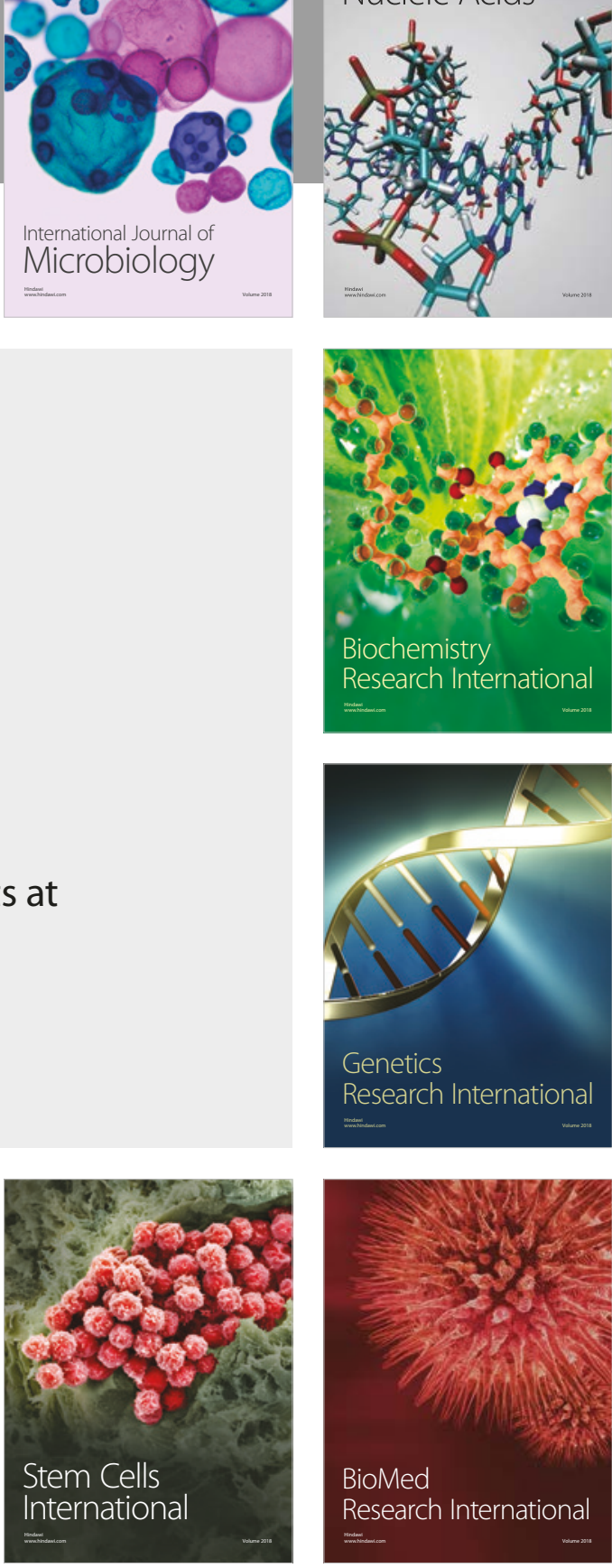
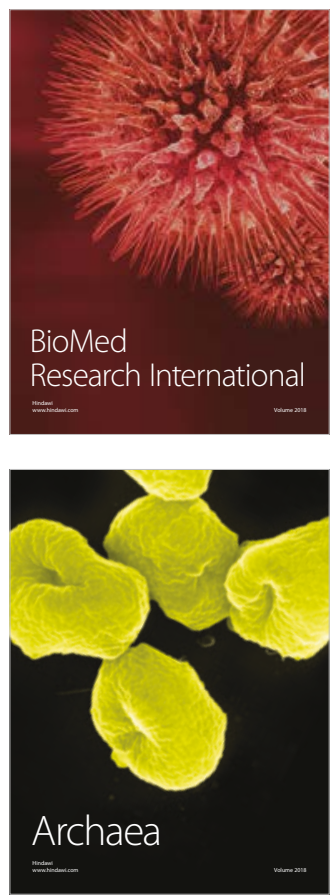